\title{
Study on Early Warning System of Coal and Gas Outburst
}

\author{
Xianglan Liu, ${ }^{1, *}$ Xusheng Zhao ${ }^{2}$ and Qinghua Zhang ${ }^{2}$ \\ ${ }^{I}$ Key Laboratory of Mine Disaster Prevention and Control, Shandong University of Science and Technology, Qingdao \\ 266590, China \\ ${ }^{2}$ Chongqing Research Institute of China Coal Technology \& Engineering Group Corporation, Chongqing, 400039, \\ China
}

\begin{abstract}
Coal and gas outburst is an extremely complex and serious gas dynamic phenomenon. Therefore, building an early warning system based on computer system, safety monitoring systems of coal mines and local area network is a precondition for effectively preventing coal and gas outburst. The early warning system for coal and gas outburst is a complicated system project and has blended together the coal mine safety theory, the information technology and the early warning technology. Combining the hardware conditions, organization management structures and characteristics of preventing outburst technology systems, this paper discusses the principle, logic structure and implementation process of gas outburst warning, devises the software and hardware structure of the warning system and therefore offers theoretical thought and methods for the forecasting of coal and gas outburst.
\end{abstract}

Keywords: Coal and gas outburst, early warning system, hardware, software.

\section{INTRODUCTION}

China has high-frequency accidents of coal mines. Coal and gas outburst is an extremely complex and serious gas dynamic phenomenon. In 2005-2010, 39 major accidents of coal and gas outburst occurred in China, including six especially severe accidents that took 295 lives. The proportion of outburst accidents and death tool is increasing year by year, which has increased gradually from $11.8 \%$ and $8.9 \%$ in 2005 to $27.6 \%$ and $46.2 \%$ in 2010 respectively. Especially in major gas accidents, the proportion outburst accidents and death tool is $54.5 \%$ and $68.2 \%$ respectively $[1,2]$. The key to control coal and gas outburst is prediction and warning for hidden outburst hazard and accident, and then the adoption of effective control measures to eliminate the danger before the accident occurs. Early warning mechanism is integration of early warning technology and crisis management system, which can evaluate the possibility and harmfulness of hazard according to the monitoring information and collected data. Therefore, it can raise the alarm at an early age to prompt decision-makers to take pre-control countermeasures and prevent the accidents to greatest extent.

\section{EARLY WARNING PRINCIPLE OF COAL AND GAS OUTBURST}

There are many complex reasons and factors in coal and gas outburst. With the continuing movement of the work face, the related factors, such as the gas geology and coal seam occurrence, are in the dynamic changes of time and

*Address correspondence to this author at the Key Laboratory of Mine Disaster Prevention and Control, Shandong University of Science and Technology, Qingdao 266590, China; Tel: 13780668857; Fax: 0532-86057626;

E-mail:ggxlyf@yahoo.com.cn space. The outburst usually breaks out suddenly and fast turns into accidents, which have a huge destructiveness. All kinds of relevant materials and information about the coal mine site and coal and gas outburst, which are scattered on the space and have various information forms, are mastered in different functional departments. The realization of coal and gas outburst warning is based on the premise that we get real-time information, central management and intelligent analysis.

The basic principle of coal and gas outburst early warning is: with the help of information and computer and network technology and based on the comprehensive and timely collection of the static and dynamic safety information and center control and information share, we make full use of the existing technical equipment and the management methods to make an intelligent, real-time and dynamic analysis about the working face dangerous condition and development trend with the development of the spatial mining and early warning analysis model, and to remind managers to take measures to prevent outburst, strengthen management and remove hidden dangers according to the automatically given warning information by the results of analysis.

\section{LOGIC STRUCTURE DESIGN OF EARLY WARN- ING SYSTEM}

The logic structure of the early warning is the relationship between the logic unit contained in the warning control process and each logic unit. Logically, a complete warning process includes six parts, just as shown in Fig. (1), which are hazards monitoring, hazards identification, warning sign identification, warning situation analysis, warning information issue, countermeasures and suggestions, implementation. 


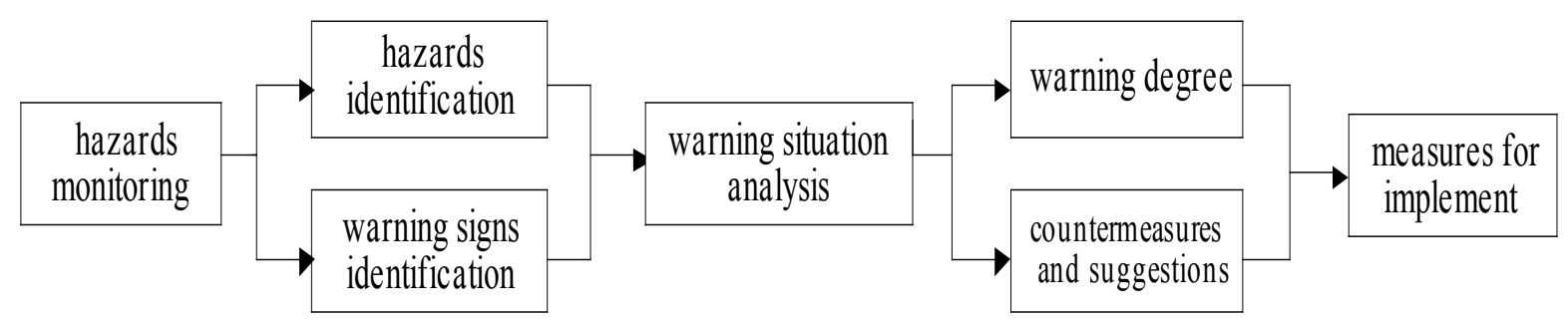

Fig. (1). Early warning logical structure.

Warning elements refer to all kinds of relevant factors of warning object such as specific disasters or accidents, including the influence factors and reflected elements. Hazards monitoring is a comprehensive and complete process, its purpose is to establish reliable safety information source, to acquire all kinds of dynamic safety information related to disaster as far as possible comprehensive, complete and timely. At the same time, it has the function of classification, storage, transmission and archiving the safety information.

Hazard is called warning source which is the root of the accidents and disaster. According to warning elements monitoring results, warning source identification is to determine the presence, status and development trend of hazards related to warning object. Warning source identification is based on the objective relationship between warning elements and warning source.

The occurrence of accidents and disasters is a process from quantitative to qualitative. A series of signs are called warning signs which appear during the process. They provide key information for the warning of accidents or disasters. Some warning signs reflect the warning source condition, and the other reflect the process of disaster occurrence and development. Warning signs identification is to filter and analyze monitoring information, to extract the signs related to warning sources and warning elements, and to provide critical information for warning situation anslysis.

Warning situation analysis is based on the identifition results of the monitoring information and warning signs, according to the analysis model of warning situation, the possibility and development trend of disasters, to determine the hazard degree. The purpose of warning situation analysis is to make timely and reliable prediction and evaluation of the disaster. Inaccurate and insufficient results are likely to affect the early warning effects. Warning situation analysis is the key to the success or failure of the entire warning, and the most difficult part of the warning process.

Warning degree indicates the dangerous level of disasters. Warning degree issue is to publish warning results through certain ways, in order to let the relevant personnel to understand the dangerous levels and development trends of disasters in a timely manner. In social production process, the publishing content of warning results should be different according to different personnel quality, needs and responsibilities. Usually the warning results issues are encountered by television, radio, internet, mobile phone text messages, and telefone and so on. The publishing content usually includes the warning level and suggestions. The publishing way includes sounds, images, text, etc.
According to early warning analysis results, the countermeasures can be used to give prevention suggestions of disasters, guide personnel to take measures and decisions. Countermeasures can usually be made on the basis of experience of experts, and can be used to set up rule database.

Warning response is to implement the corresponding response measures timely, effectively and completely in an automated manner or artificially, to eliminate various factors that lead to hazardous events, to take prevention and protection measures timely, and to avoid accidents or reduce the damage caused by the accident.

\section{IMPLEMENTATION PROCESS OF EARLY WARNING SYSTEM}

According to the colliery safety monitoring system, maintenance and management of LAN and functional departments, and in order to realize the prediction of coal and gas outburst, we need to monitor the main dangerous resources of the coal and gas outburst to get the safety information, such as coal seam hosting, geological structure distribution, roadway layout, space position of face, information from gas-geology around the face and the information of stress concentration, gas emission, daily forecast, the performance of outburst prevention measures, effect test of outburst prevention measures, forecast equipment and violation etc. The safety information is divided into static and dynamic safety information; the former is obtained by the digitalization process of mines, while the later is obtained by the monitoring system and LAN. All of the information is mastered by the different departments and we need to build a centralized comprehensive database to share and manage and to renew information, identify and analyze the safety information and calculate the related warning index, and make grade division through various warning rules in the database. Information identification, analysis and judgment should be completed by warning servers and professional analysis software, and the warning results should be issued by network, sound and light alarm, message and so on [3]. The implementation process is shown in Fig. (2).

\section{HARDWARE STRUCTURE DESIGN OF EARLY WARNING SYSTEM}

Hardware structure of warning system is composed of monitoring system servers, office local area network, warning server, computer terminals and notification appliance. According to the warning database management process, we integrate the related data down the mine forming the different functional departments by the help of professional software, and construct the comprehensive warning platform of 


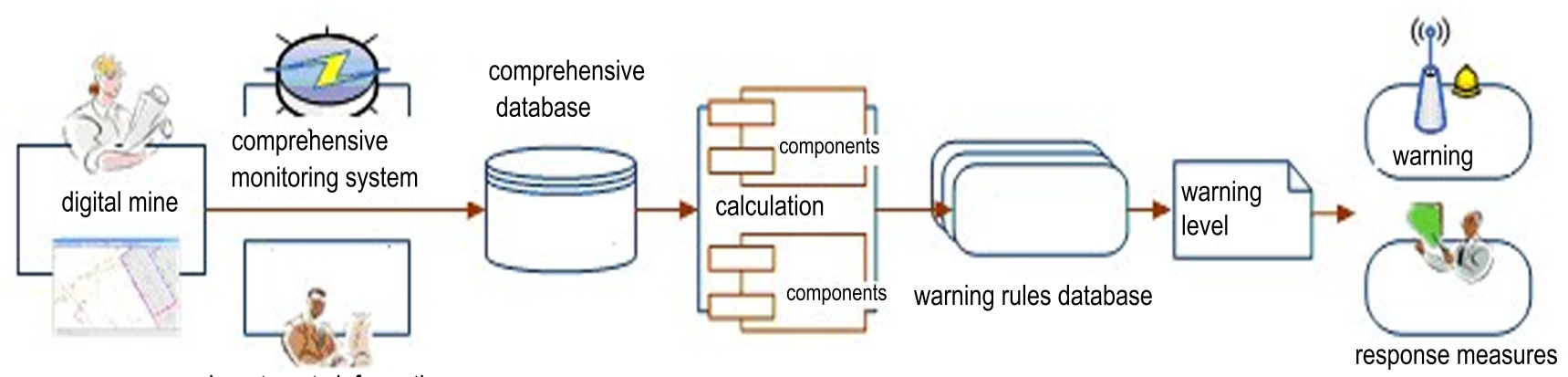

departments information

Fig. (2). Implementation process of early warning for coal and gas outburst.

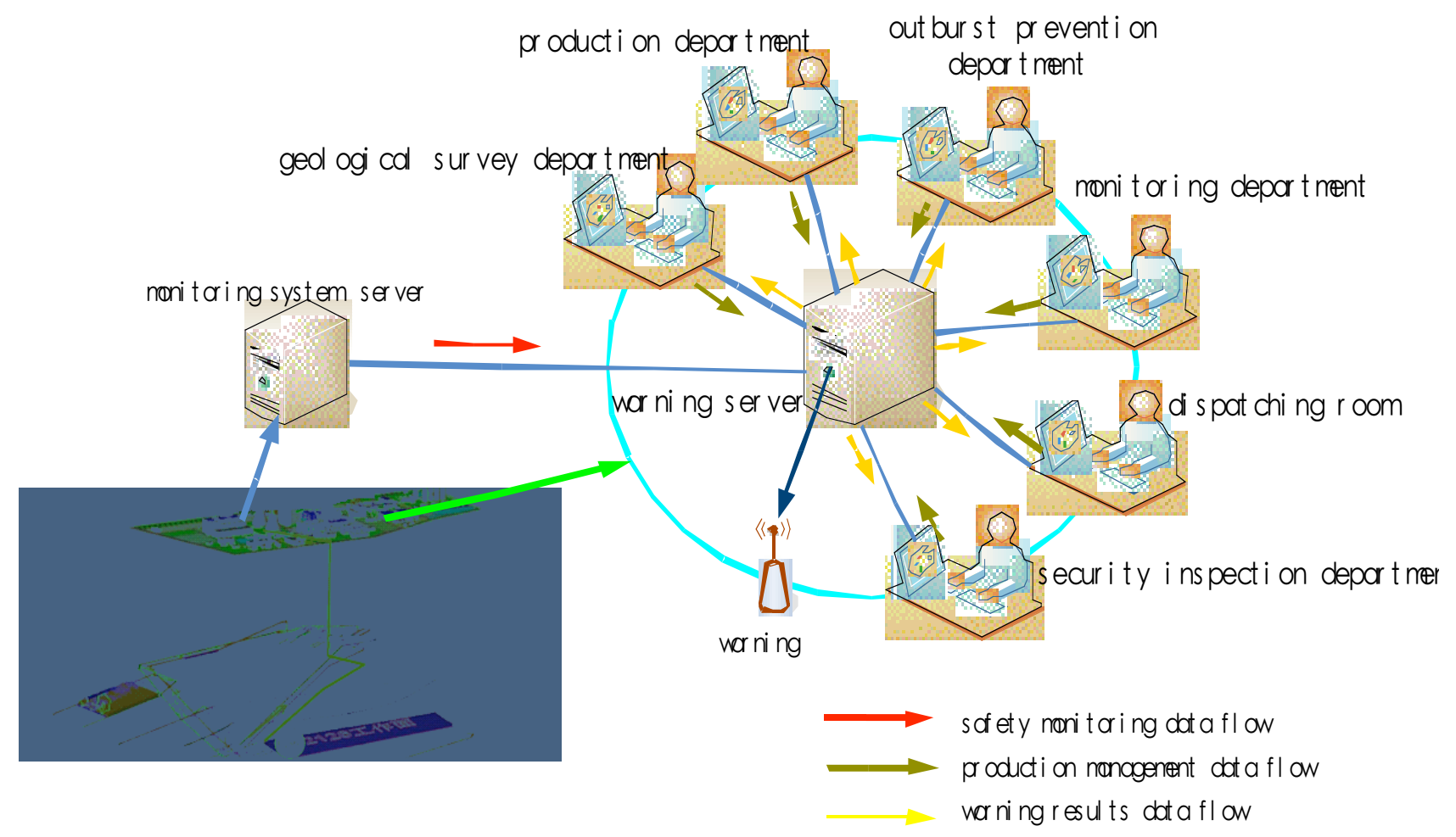

Fig. (3). Structure diagram of early warning system.

coal and gas outburst on the basis of realizing the centralized management and sharing of the safety information. Structured process is shown in Fig. (3).

Hardware is the carrier and environment support of warning software, whose logical structure is structured by data input, data transfer, data analysis, data output etc. The main hardware equipments mainly include warning server, office local area network, office local area network, mobile notification appliance and so on.

Monitoring system server mainly provides real time information, i.e. security environment monitoring parameters. Office local area network mainly manages the transport of important dynamic security information that cannot be monitored, and the issue of warning results. Warning server mainly provides large database storage, safety information analysis and warning instructions. Computer terminal takes on the warning subsystem operation, dynamic security information inputting, warning results show and history infor- mation querying of warning. Mobile notification appliance is used for sending out warning results and information to the mine technicians of safety management [4]. Combining the above hardware equipment and environment, the hardware platform of the warning system is constructed, as shown in Fig. (4).

\section{TABLES, FIGURES AND EQUATIONS}

The warning software system of the coal and gas outburst is the core of the comprehensive early warning, which is composed of the user management system, hazards and warning signs management system, warning situation analysis and warning degree management and warning response management system, as shown in Fig. (5).

\subsection{The User Management System}

According to the different duty of the mine workers, the early warning system sets special operation authority and 


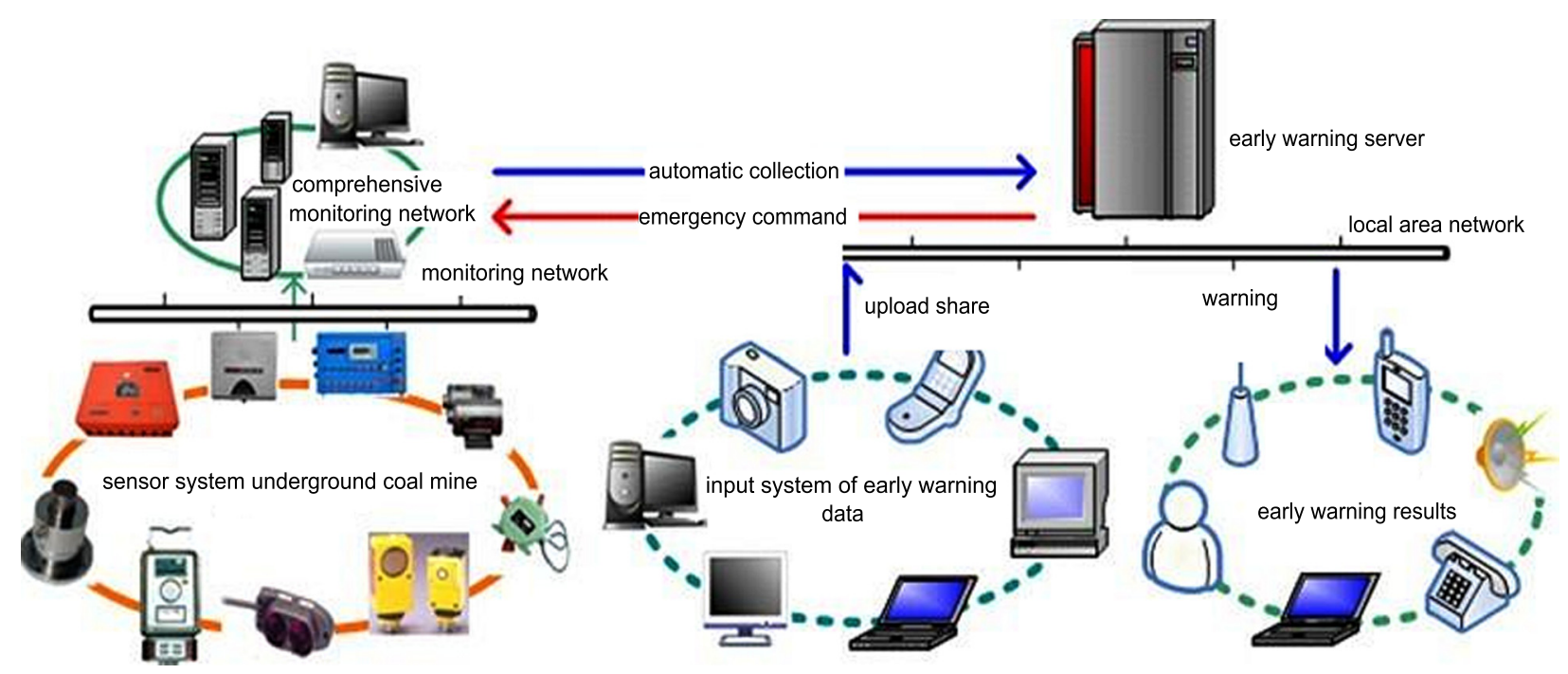

Fig. (4). Framework of hardware platform.

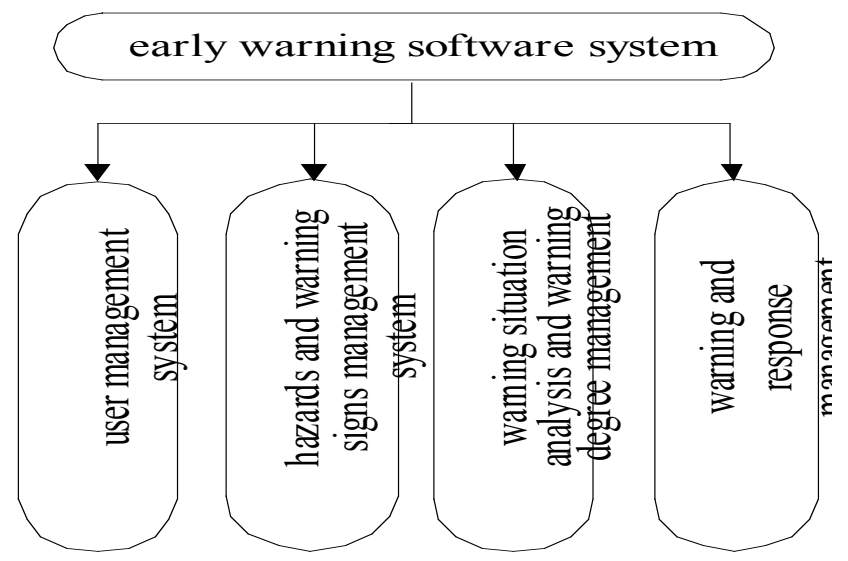

Fig. (5). Composition of early warning software system.

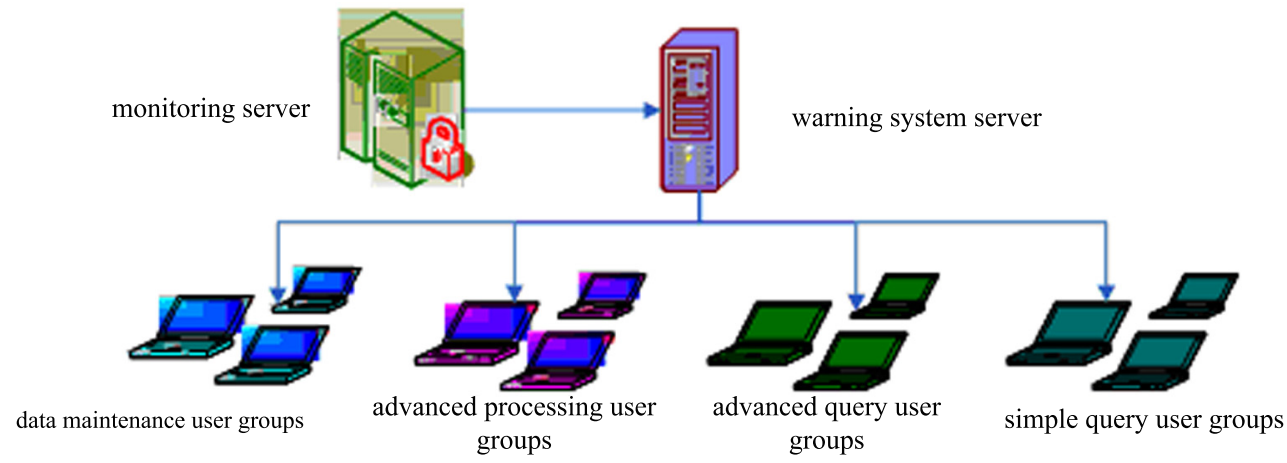

Fig. (6). Manage system for early warning users.

receiving grade of early warning results, which is shown in Fig. (6). Based on the building structure and objectives of platform of coal and gas outburst, the authority function and distribution mode of individual users are described below:

Data maintenance user group is general from two to four. The operation authority is to maintain data update; the users are from geological measurement department, ventilation department and technique department.

Advanced early warning process user group is general from three to ten. The operation authority is to go on alert actions on the basis of existing data and publish warning results to network. The users can be technical personnel and the chief engineer. More importantly, only 1 senior user can modify the published object about warning index, rules and warning levels.

The operation authority of the usual query user group can query and output part of the early warning results and data.

\subsection{Warning Sources and Signs Management System}

According to the organization structure and work contents of coal mine functional departments, the early warning 


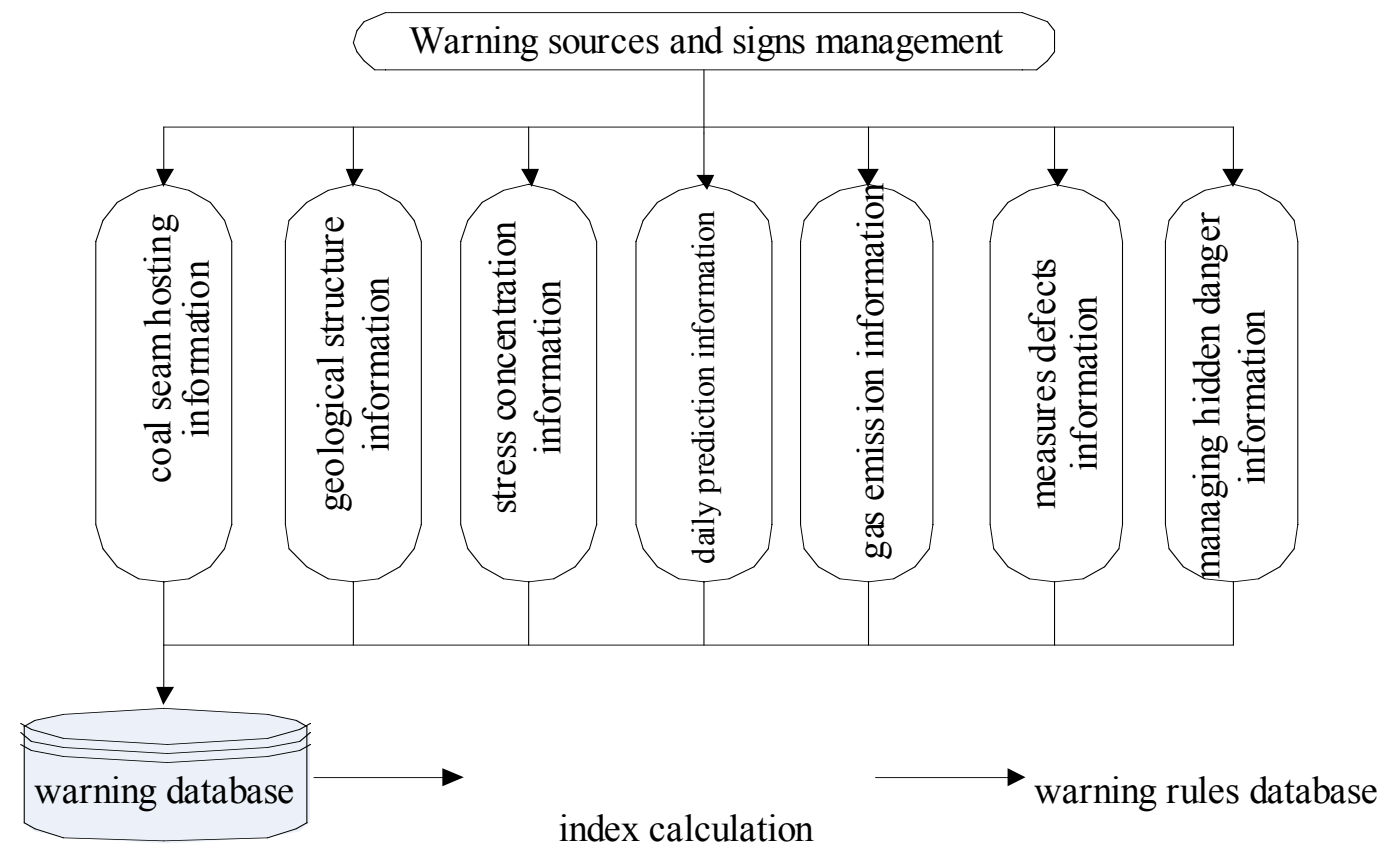

Fig. (7). Management system of warning sources and signs.

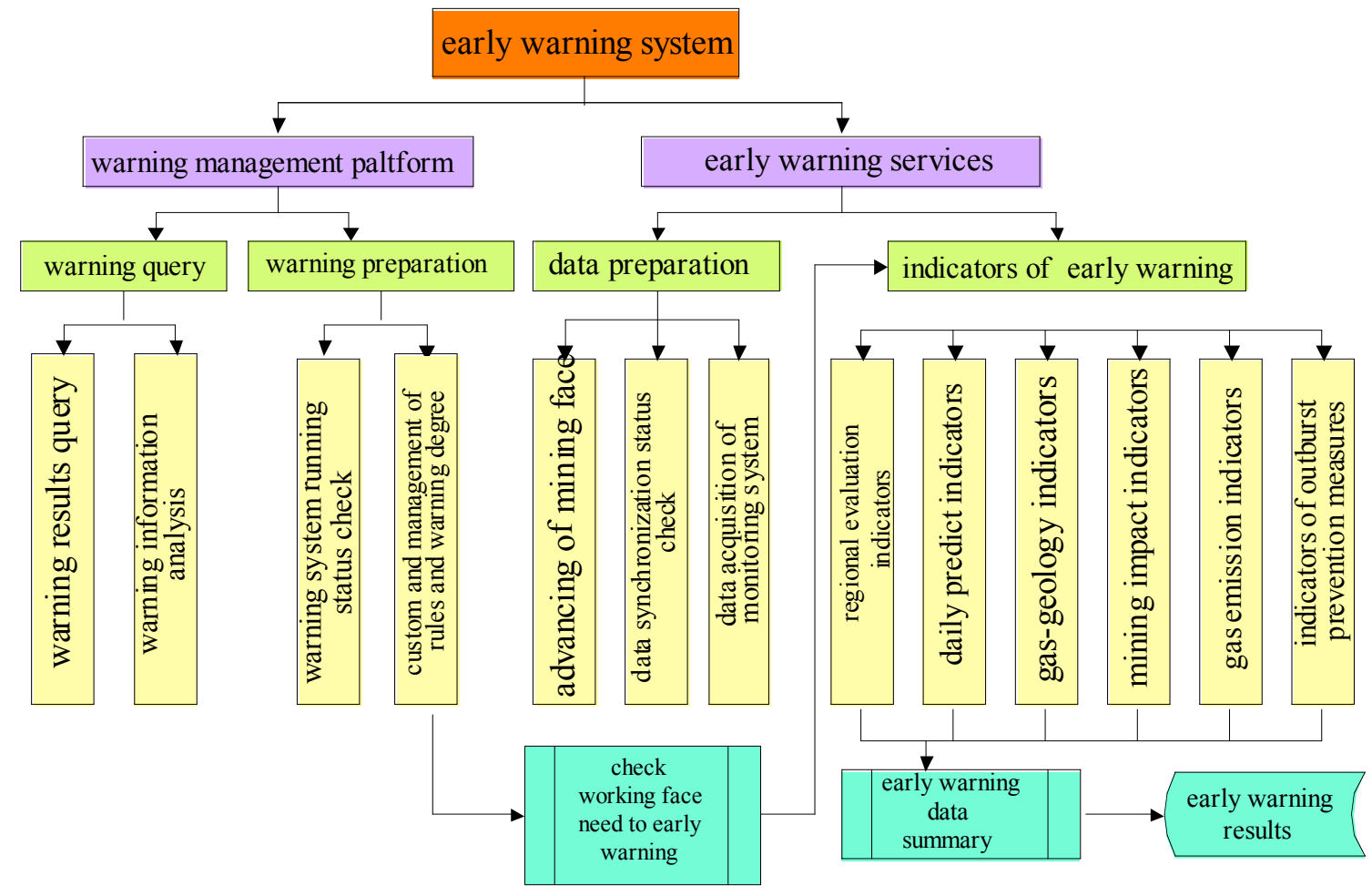

Fig. (8). Architecture of warning situation analysis and warning level management.

system establishes warning sources and signs management system as shown in Fig. (7). Warning sources management system includes acquisition, transfer and collection of security information. The system uses a semi-automatic way to obtain and process information. Monitoring data is collected automatically through the coal mine safety monitoring system, the production and management data is manually entered by corresponding functional departments. The warning signs analysis system, as an important link in the early warning process and by deeply excavating the basic data and safety information of the comprehensive early warning database, screens and recognizes effective information and calculates the corresponding early warning indicators.

\subsection{Warning Situation Analysis and Warning Degree Management System}

The structure of warning situation analysis and warning degree management is shown in Fig. (8). The comprehensive early warning system consists of two parts: the warning management platform and early warning services. The warn- 
Table 1. Emergency Level of Early Warning

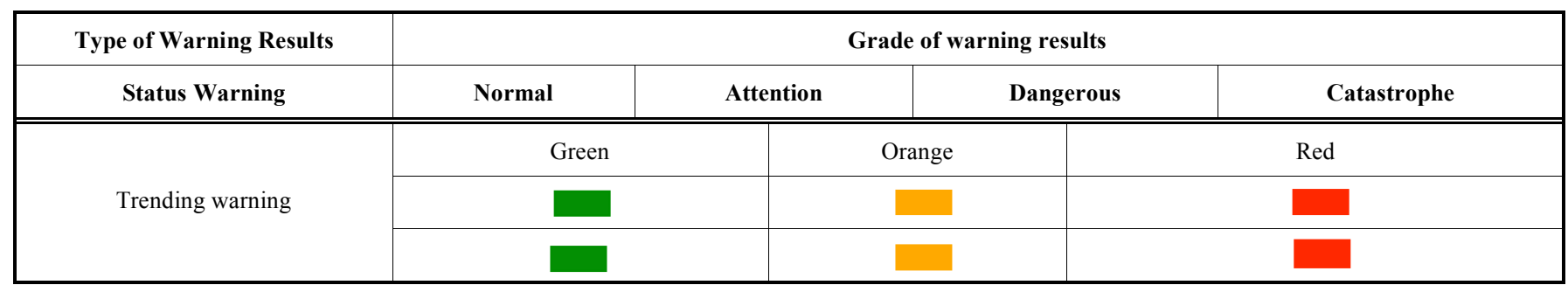

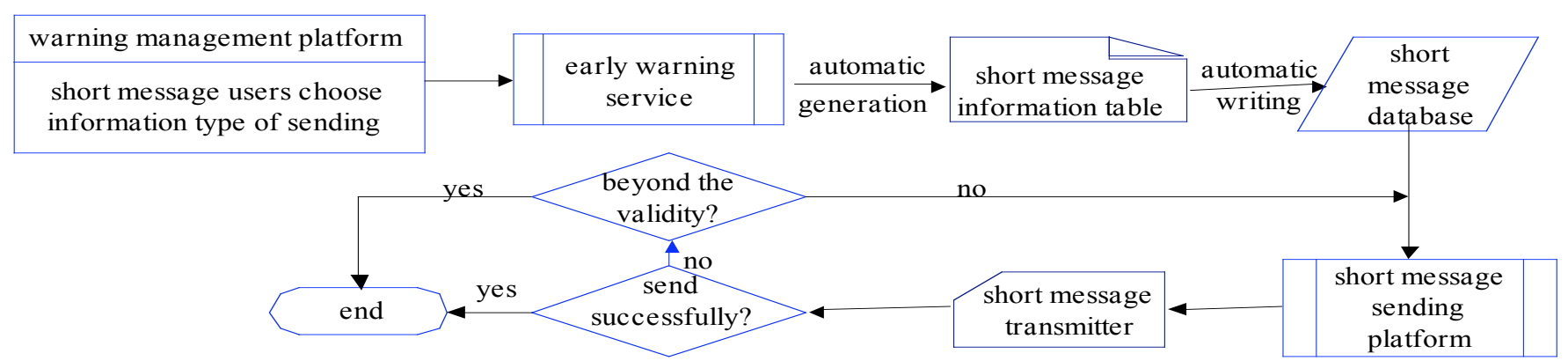

Fig. (9). Logical structure of warning message sending system.

ing management platform is mainly used to choose and custom warning rules and display forms of warning degree, query and analyze warning results and information, check the operating status of the early warning system, and give warnings and suggestions of operating faults. Comprehensive early warning services include two parts: data preparation and implementation of early warning. Data preparation is to confirm the basic information and connection of monitoring equipment prior to outburst warning of the working face, and then analyze, in the mining process its dangerous condition and trend based on early warning indicators, rules and models.

The warning degree directly sends dynamic safety signals to the user's working face. The display forms of warning degree employ two formats: the degree output based on a comprehensive model and the single factor time-order degree output. The degree output based on a comprehensive model, in accordance with the dangerous scales of coal and gas outburst, demonstrates the status and trends of warning degree in words and in color respectively as shown in Table 1. For each result of warning degree, descriptive terms are given to explain the warning condition and to analyze basis in accordance with sources, signs and conditions of early warning.

\subsection{Warning Issue and Response Management System}

The warning issue system is mainly used for sending warning signals to relevant departments and personnel when the early warning degree amounts to the set value, and customizing different warning issue measures according to requirements of warning degree. When the warning results of working face are at the "normal" level, the warning issue system will show the warning degree in green indicating no warning and will not send out the warning information. When the warning results of working face are at the "abnormal" level, the system will send different signals according to different user types. For general users, the system will show the warning degree in brunet fonts and colors, and is- sue warning through the web page. For main users such as the technical personnel of outburst prevention, warning results will be issued by sound, photoelectric signals and short messages through the warning management platform. For key users such as leaders of coal mines and persons in charge of outburst prevention, the warning will be issued in real time by short message services. The warning message sending system is shown in Fig. (9).

The warning response management system consists of two parts: daily monitoring and risk management. The daily monitoring system exercises special monitoring and control over signs of accidents, which are realized through the warning sources and signs management system and the warning situation analysis system. The risk management system is employed to take measures when outburst risks exist or disasters occur on the working face. First, by using the risk management system, it sends warning information to different departments and leaders in accordance with the warning degree information. Then, on the basis of the overall measures taken and the effects of outburst-removing measures in particular, it reanalyzes the safety status and issues of new warning results in order to determine whether mining can be allowed. The risk management system structure is shown in Fig. (10).

\section{CONCLUSIONS}

The warning system of coal and gas outburst is a new method and a new means to guarantee safety in coal mines, and also a complicated and systematic project which combines the safety theory of coal mines, the information technology, GIS technology and the early warning theory. On the basis of a systematic study of the specific characteristics and laws of mining disasters, it employs safety monitoring systems of coal mines and local network conditions and adopts a series of professional analysis software as its carrier. As a technological system of early warning that accords with min- 


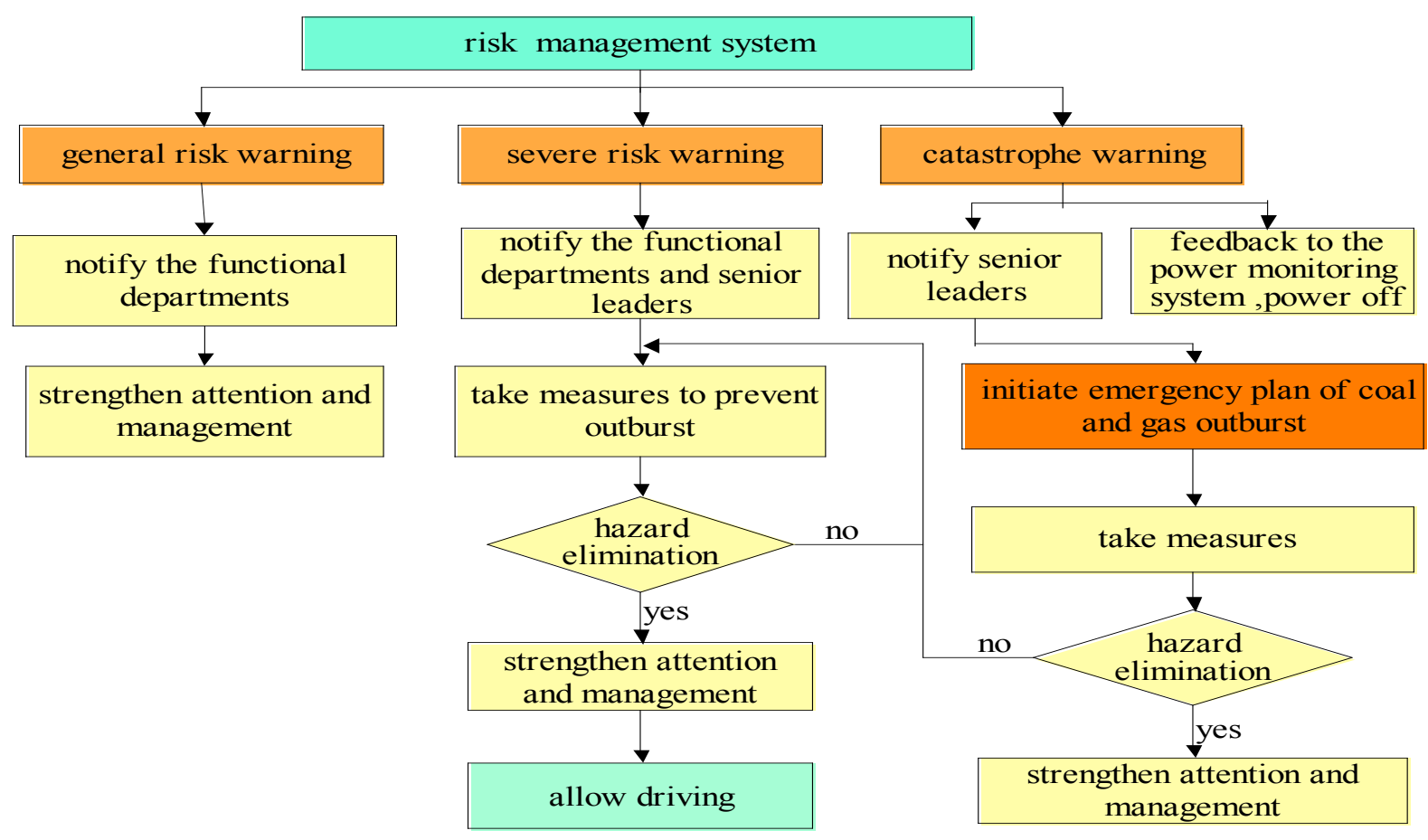

Fig. (10). Structure of emergency management for early warning.

ing production, it is of great realistic significance for forecasting and reducing accidents of coal and gas outbursts.

\section{CONFLICT OF INTEREST}

The authors confirm that this article content has no conflicts of interest.

\section{ACKNOWLEDGEMENTS}

This work was financially supported by the national science and technology supporting plan of the twelfth five-year of China (2012BAK04B01) and national natural science foundation project of China (51174129).

\section{REFERENCES}

[1] Chongqing Research Institute of China Coal Technology \& Engineering Group Corporation. Research report on early warning technique of ventilation gas hazards [R].2010. (In Chinese)

[2] Z. Xusheng, Z. Yunlong, "Accident cause analysis and countermeasure of coal and gas outburst nearly two years of our country," Min. Saf. Environ. Prot., vol. 37, no. 1, pp. 84-87, 2010.

[3] L. Cheng, Z. Xusheng, "The comprehensive solutions of gas disaster warning technology and computer system construction", Min Saf. Environ. Prot., vol. 36, no. 8, pp. 60-64, 2009.

[4] L. Xianglan, Z. Xusheng, G. Dong, "Research on early warning system for coal and gas outburst", ICMHPC, pp. 560-568, 2010.

Received: July 02, 2013

(C) Liu et al.; Licensee Bentham Open.

This is an open access article licensed under the terms of the Creative Commons Attribution Non-Commercial License (http://creativecommons.org/licenses/by-nc/3.0/) which permits unrestricted, non-commercial use, distribution and reproduction in any medium, provided the work is properly cited. 